\title{
Sialendoscopy Combined With Transoral Sialodochoplasty for the Treatment of Parotid Duct Stenosis With a Megaduct
}

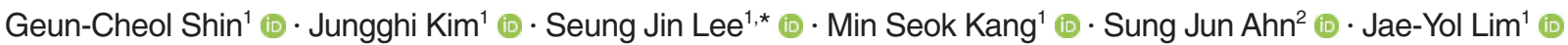 \\ Departments of ${ }^{1}$ Otorhinolaryngology and ${ }^{2}$ Radiology, Gangnam Severance Hospital, Yonsei University College of Medicine, Seoul, Korea
}

Salivary duct stenosis is the second most common (15\%-50\%) cause of chronic obstructive sialadenitis, following sialolithiasis [1]. It is associated with chronic inflammatory changes induced by allergy, stones, trauma, an autoimmune response, or radioiodine therapy $[2,3]$. This condition often leads to reduced salivary flow, ascending duct infection, the formation of mucous or fibrous plaques, and strictures in salivary gland ducts [4]. Sialendoscopy allows a direct examination of the tissue characteristics of stenotic lesions. Koch et al. [5,6] described the following three types of stenosis: inflammatory (type 1), web-like or circular (type 2), and fibrotic or diffuse (type 3) luminal narrowing. Type 1 appears to be a precursor of type 3 stenosis, showing a progressive diffuse narrowing in the segmental or entire duct [5]. In contrast, type 2 stenosis typically tends to form a focal stricture accompanied by a megaduct due to dilation secondary to mechanical obstruction.

The sialendoscopic approach is safe and effective for treating patients with salivary duct stenosis $[4,7,8]$. However, resolving the stenotic ducts remains a surgical challenge if sialendoscopy fails to dilate the stenotic lesions mechanically. The so-called transoral (pull-through) sialodochoplasty, a surgical technique to remove the stenotic portion of an involved duct and connect the remaining duct to the buccal mucosa, has been described in several reports $[9,10]$. However, the efficacy of transoral sialodochoplasty has not yet been investigated. This study aimed to analyze

- Received November 17, 2020

Revised December 28, 2020

Accepted January 11, 2021

- Corresponding author: Jae-Yol Lim

Department of Otorhinolaryngology, Gangnam Severance Hospital, Yonsei

University College of Medicine, 211 Eonju-ro, Gangnam-gu, Seoul 06273,

Korea

Tel: +82-2-2019-3460, Fax: +82 2-3463-4750

E-mail: jylimmd@yuhs.ac

*Current affiliation: Division of Speech Pathology and Audiology, Hallym University, Chuncheon, Korea the surgical outcomes of sialendoscopy combined with transoral sialodochoplasty for the treatment of patients with type 2 parotid duct stenosis.

Patients who underwent sialendoscopy with sialodochoplasty from March 2017 to November 2019 were retrospectively selected after obtaining approval of the Institutional Review Board of Gangnam Severance Hospital (IRB No. 2020-0677-001). Owing to the retrospective design, the requirement for informed consent was waived. Patients with type 2 stenosis in the Stensen duct, which indicates a focally located stricture and accompanying megaduct on a preoperative radiological evaluation, were then selected. Among them, patients with accompanying sialolithiasis or any other underlying causes, such as Sjögren syndrome or previous radioiodine therapy, were excluded.

The surgical procedures were performed under general anesthesia with nasotracheal intubation. Salivary dilators were used to dilate the orifice of the Stensen duct. A $1.3-\mathrm{mm}$ or $1.6-\mathrm{mm}$ (diameter) sialendoscope (Karl Storz, Tuttlingen, Germany) was then inserted into the duct. Transoral sialodochoplasty was combined with sialendoscopy when sialendoscopic findings suggested high-grade strictures at high risk of recurrence or complication. A circumferential incision was made around the orifice and dissection was performed. After finding the stenotic lesion and accompanying megaduct, the megaduct was released from the buccal space (Fig. 1A). The megaduct was then pulled into the oral cavity and an incision was made on the megaduct wall with a \#15 blade (Fig. 1B). The duct distal to the stenotic area was excised, and the wall of the megaduct was sutured to the surrounding buccal mucosa with 4.0 Vicryl sutures (Fig. $1 \mathrm{C}$ and D). Sialendoscopy confirmed the integrity of the duct, and a 18-G Vinca needle sheath (KM Healthcare, Guri, Korea) was placed through a neo-orifice and maintained for 2 weeks after the operation.

Preoperative and postoperative obstructive symptoms, such as swelling and discomfort or pain during or between meals, were assessed using a 3-point Likert-type scale 3 months postopera-

Copyright (C) 2021 by Korean Society of Otorhinolaryngology-Head and Neck Surgery.

This is an open-access article distributed under the terms of the Creative Commons Attribution Non-Commercial License (https://creativecommons.org/licenses/by-nc/4.0)

which permits unrestricted non-commercial use, distribution, and reproduction in any medium, provided the original work is properly cited. 

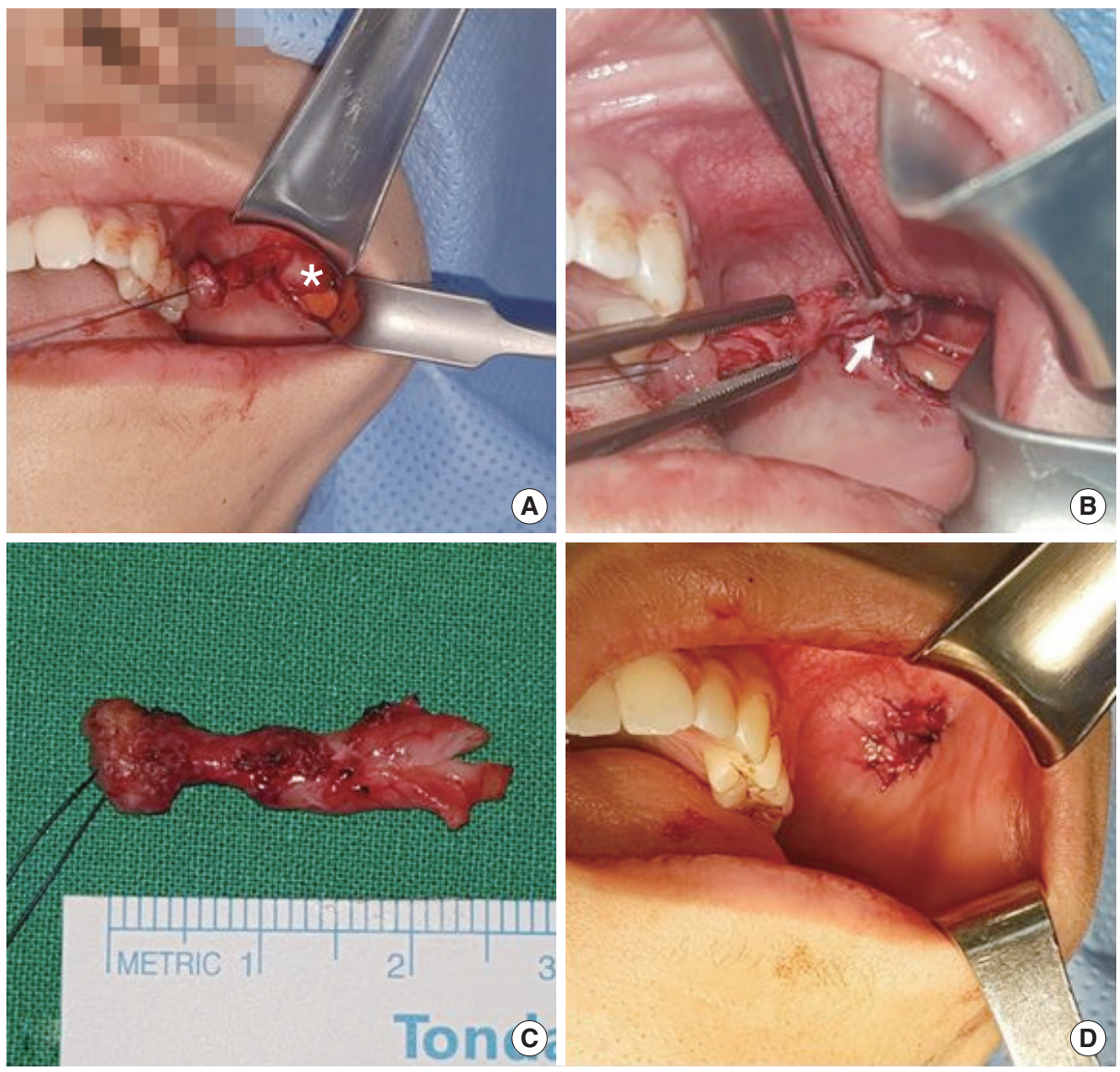

Fig. 1. Surgical procedure of transoral sialodochoplasty. (A) The stenotic portion and accompanying megaduct (asterisk) are pulled into the oral cavity after circumferential incision around the papilla and dissection along the parotid duct. (B) The stenotic lesion (arrow) is exposed with an incision onto the ductal wall. (C) Excised distal duct with stenotic lesion. (D) Creation of a neo-orifice by suturing the wall of the megaduct onto the buccal mucosa.

tively.Treatment outcomes were classified as complete resolution (the obstructive symptoms completely subsided), partial resolution (the symptoms partially improved), or non-resolution (the symptoms did not change or worsened). Magnetic resonance (MR) examinations were performed to evaluate changes in the stenotic portion and accompanying megaduct using a 3.0 T MR imaging scanner (Discovery 750W; GE Healthcare, Milwaukee, WI, USA). The largest diameter of the megaduct portion was measured on preoperative and postoperative MR images. Postoperative visualization of the distal duct beyond the stenotic portion was considered as showing improved excretory flow through the site of the stricture. Statistical analyses were performed using IBM SPSS ver. 25.0 (IBM Corp., Armonk, NY, USA). The MannWhitney $U$-test was used to compare the preoperative and postoperative diameters of the megaduct on MR sialography. A $P$ value $<0.05$ was considered to indicate statistical significance.

Of 27 patients ( 35 glands) who had type 2 stenosis in the distal parotid duct, 13 patients (13 glands) underwent combined transoral sialodochoplasty and were finally enrolled. Patients' ages ranged from 13 to 68 years (median, 52 years), and there were seven male (54\%) and six female (46\%) patients. All 13 patients presented with swelling of the affected salivary gland, which was accompanied by pain in one patient and discomfort in two patients. At 3 months postoperatively, six patients (46.2\%) reported no remaining symptoms (complete resolution), and seven patients $(53.8 \%)$ reported partial improvement of symptoms (partial resolution). The postoperative megaduct diameter on MR sialography significantly decreased after transoral sialodochoplasty (median \pm interquartile range, $8.05 \pm 2.67 \mathrm{~mm}$ vs. $4.15 \pm 2.4 \mathrm{~mm} ; P=0.028$ ). In addition, we found that the distal ducts were visualized using a sialagogue (vitamin $\mathrm{C}$ ) postoperatively (Fig. 2). No recurrence was observed during follow-up (17 \pm 9 months).

Sialendoscopy has enabled the assessment of ductal features and changed the therapeutic modality in salivary duct stenosis to gland-preserving minimally invasive surgery $[4,6]$. However, stenosis type and grade are significantly associated with the success of the sialendoscopic procedure [7]. In this study, transoral sialodochoplasty was feasible when the stenotic portion was distally located and the dilated duct could be pulled to connect with 

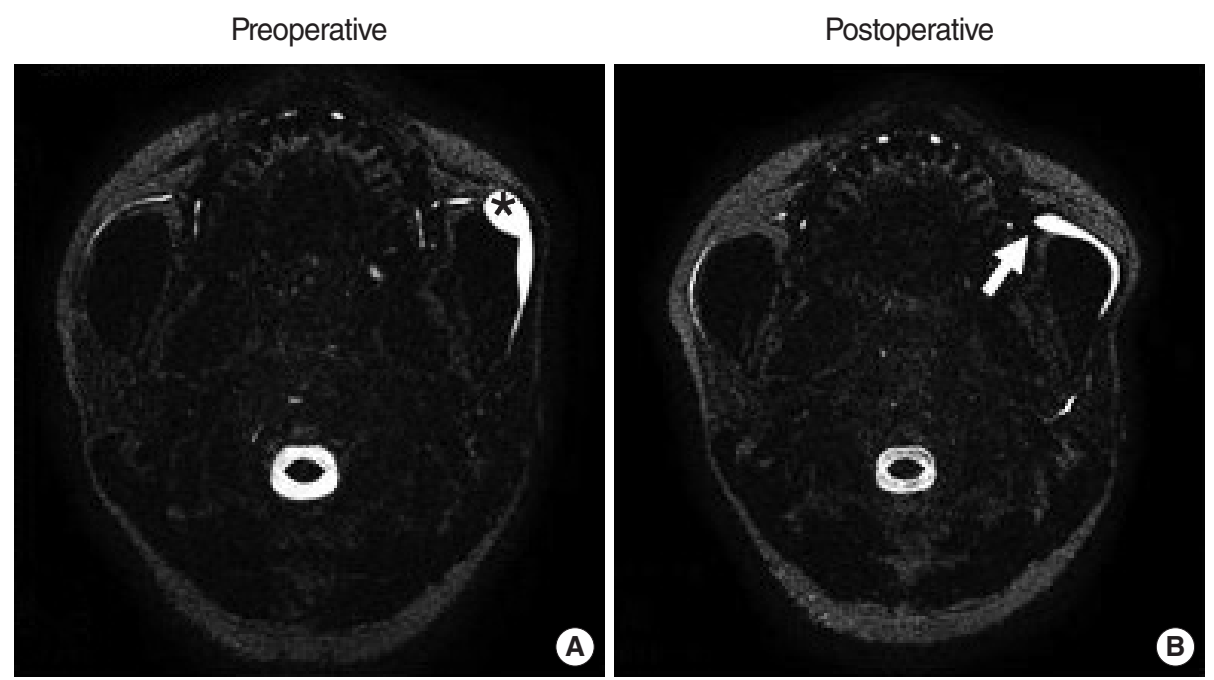

Sialodochoplasty

Fig. 2. Preoperative and postoperative magnetic resonance (MR) sialographic findings of parotid duct stenosis with secondary dilated megaducts, before and after transoral sialodochoplasty. (A) Preoperative MR sialographic image depicts a parotid duct stricture with an accompanying megaduct (asterisk). (B) Arrow indicates visualization of the distal duct after surgery, suggesting improvement in saliva excretion through the previous stricture site.

the oral mucosa. Excision of the distal duct, including the stenotic portion, and the creation of a neo-orifice enabled obstructive symptom improvement. Moreover, the widened neo-papilla decreased in size over time and was maintained well during followup without re-stricture. We also compared preoperative and postoperative changes in the megaduct diameter and excretory salivary flow. Intriguingly, postoperative MR sialography showed that the diameter of megaducts significantly decreased after transoral sialodochoplasty, and some of the patients (71.4\%) returned to almost normal levels. MR sialography showed the distal parotid ducts more clearly after the operation, owing to the increased saliva excretion in response to stimulation by a sialogogue. However, some patients still showed saliva stasis-related discomfort, probably because the megaducts' thin walls could not fully recover their original contraction ability. In conclusion, we suggest that transoral sialodochoplasty can be an additional treatment option if a stricture is located in the distal duct based on preoperative radiological examinations and if sialendoscopic findings reveal high-grade type 2 stenosis accompanying a large megaduct.

\section{CONFLICT OF INTEREST}

No potential conflict of interest relevant to this article was reported.

\section{ACKNOWLEDGMENTS}

The Basic Science Research Program supported this work through the NRF funded by the Ministry of Science and ICT (NRF-2018R1A2B3004269), Republic of Korea.

\section{ORCID}

Geun-Cheol Shin https://orcid.org/0000-0003-0341-4711

Jungghi Kim https://orcid.org/0000-0002-6591-1732

Seung Jin Lee https://orcid.org/0000-0001-6200-0004

Min Seok Kang https://orcid.org/0000-0002-7147-900X

Sung Jun Ahn https://orcid.org/0000-0003-0075-2432

Jae-Yol Lim https://orcid.org/0000-0002-9757-6414

\section{AUTHOR CONTRIBUTIONS}

Conceptualization: JYL. Data curation: JK. Formal analysis: SJL, SJA. Project administration: MSK. Visualization: GCS. Writing-original draft: GCS. Writing-review \& editing: JYL.

\section{REFERENCES}

1. Maresh A, Kutler DI, Kacker A. Sialoendoscopy in the diagnosis and management of obstructive sialadenitis. Laryngoscope. 2011 Mar; 121(3):495-500.

2. Koch M, Zenk J, Bozzato A, Bumm K, Iro H. Sialoscopy in cases of unclear swelling of the major salivary glands. Otolaryngol Head Neck Surg. 2005 Dec;133(6):863-8.

3. Choi JS, Kim YM, Lim JY. Parotid ductal stenosis after facial cosmetic surgery (2 case reports). Medicine (Baltimore). 2019 Apr;98(15): 
e15015.

4. Koch M, Iro H, Zenk J. Role of sialoscopy in the treatment of Stensen's duct strictures. Ann Otol Rhinol Laryngol. 2008 Apr;117(4):271-8.

5. Koch M, Iro H. Extended and treatment-oriented classification of parotid duct stenosis. Laryngoscope. 2017 Feb;127(2):366-71.

6. Koch M, Iro H, Zenk J. Sialendoscopy-based diagnosis and classification of parotid duct stenoses. Laryngoscope. 2009 Sep;119(9):1696703.

7. Choi JS, Choi YG, Kim YM, Lim JY. Clinical outcomes and prognostic factors of sialendoscopy in salivary duct stenosis. Laryngoscope. 2018 Apr;128(4):878-84.
8. Plonowska KA, Gurman ZR, Humphrey A, Chang JL, RyanWR. Oneyear outcomes of sialendoscopic-assisted salivary duct surgery for sialadenitis without sialolithiasis. Laryngoscope. 2019 Apr;129(4): 890-6.

9. Salerno S, Lo Casto A, Comparetto A, Cannizzaro F, Barresi B, Speciale R, et al. Sialodochoplasty in the treatment of salivary-duct stricture in chronic sialoadenitis: technique and results. Radiol Med. 2007 Feb;112(1):138-44.

10. Kandl JA, Ong AA, Gillespie MB. Pull-through sialodochoplasty for Stensen's megaduct. Laryngoscope. 2016 Sep;126(9):2003-5. 